\title{
PEMANFAATAN BIG DATA MARKETPLACE TERHADAP PROFIL EKONOMI DIGITAL DAERAH SEKTOR PERDAGANGAN DI KALIMANTAN BARAT, INDONESIA
}

\author{
(The Usage of Big Data Marketplace To The Digital Economic Profile of The Trade Sector \\ In West Kalimantan, Indonesia)
}

\author{
Dandy Adetiar Al Rizki ${ }^{1}$, Usman Bustaman'2, Setia Pramana ${ }^{1,2}$ \\ Politeknik Statistika STIS, Jakarta ${ }^{1}$ \\ Subdirektorat Pengembangan Model Statistik, Badan Pusat Statistik, Jakarta ${ }^{2}$ \\ Jalan Otto Iskandardinata No.64C 1 4, RT.1/RW.4, Bidara Cina, Kecamatan Jatinegara, Kota Jakarta Timur, \\ Daerah Khusus Ibukota Jakarta 13330 \\ E-mail: ${ }^{1}$ dandy.adetiar@gmail.com, ${ }^{1,2}$ setia.pramana@stis.ac.id
}

\begin{abstract}
ABSTRAK
Ekonomi digital lahir dan berkembang seiring penggunaan teknologi informasi dan komunikasi yang juga semakin mengglobal di dunia. Keberadaan ekonomi digital ditandai dengan semakin maraknya perkembangan bisnis atau transaksi perdagangan yang memanfaatkan internet sebagai media komunikasi, kolaborasi, dan kooperasi antar perusahaan ataupun individu. Dalam mewujudkan pembangunan ekonomi nasional pemerintah perlu memberikan insight untuk menjadi bahan dasar edukasi kepada berbagai pihak dengan memanfaatan Big Data penjualan pada marketplace dalam membentuk profil ekonomi digital daerah. Penelitian dilakukan dengan pendekatan kualitatif menggunakan deskriptif kualitatif metodologi visual site of self, dimana peneliti bertindak sendiri untuk melakukan interpretasi, pemaknaan dan pemahaman terhadap obyek penelitian yang diamati. Pertumbuhan penjualan online dengan Januari sebagai bulan dasar menunjukkan tren naik di Kalimantan Barat hal ini merepresentasikan bahwa ekonomi digital di kalimantan barat dapat tumbuh dan berkembang serta mempengaruhi keadaan ekonomi masyarakat. Ditinjau dari kategori yang telah dikumpulkan banyak kategori yang mengalami pelonjakan dalam pertumbuhan penjualannya dengan Januari sebagai bulan dasarnya. Big Data penjualan pada salah satu marketplace menunjukkan distribusi harga produk yang relatif tersebar dengan selisih yang tidak terlalu besar antar kabupaten/kota di Kalimantan Barat. Produk terbanyak yang terjual di Kalimantan Barat didominasi oleh kategori Voucher dengan jenis barang Pulsa \& Data, Voucher Gaming, dan Voucher Belanja termasuk didalamnya Voucher Listrik, Gas, \& Air. Kota Pontianak tercatat sebagai daerah dengan penjualan barang terbanyak melalui kategori Perawatan \& Kecantikan sebagai komoditasnya dan jenis produk terbanyak berupa Kosmetik Wajah.
\end{abstract}

Kata kunci: Big Data, Ekonomi digital, Marketplace, Profil Ekonomi

\section{ABSTRACT}

The digital economy was born and developed along with the use of information and communication technology which also has globally increased. The existence of digital economy is marked by the increasing number of business developments or trade transactions using internet as a medium of communication, collaboration and cooperation among companies and individuals. In realizing national economic development, the government needs to provide insights as the basic materials to educate various parties by using Big Data sales on the marketplace to create the regional digital economic profile. The research was conducted with a qualitative approach using a qualitative descriptive visual site of self-methodology, the researcher acts alone to interpret, meaning and understand the object of the study being observed. The growth of online sales with January as the base shows an increasing trend in West Kalimantan, this represents that the digital economy in West Kalimantan can grow, develop, and affect the community economic situation. In term of categories that have been collected, many categories experienced an increase in sales growth with January as the base month. Big data for one of the marketplaces sales shows the distribution of product prices relatively spread over a range with a difference that is not too large among districts / cities in West Kalimantan. The largest number of products sold in West Kalimantan are dominated by Voucher category, with items such as Credit \& Data, Gaming Vouchers, and Shopping Vouchers including Electricity, Gas, \& Water Vouchers. Pontianak City as the region with the most sales through the Beauty \& Care category as a commodity and the largest type of product is Facial Cosmetics.

Keywords: Big Data, Digital economy, Economic Profile, Marketplace 


\section{PENDAHULUAN}

\section{Latar Belakang}

Ekonomi digital lahir dan berkembang seiring penggunaan teknologi informasi dan komunikasi yang juga semakin mengglobal di dunia. Tapscott, seorang pakar ekonomi digital, (1998) menjelaskan ekonomi digital sebagai sebuah sosiopolitik dan sistem ekonomi yang memiliki ciri sebagai sebuah ruang intelijen, meliputi informasi, berbagai akses instrumen informasi dan pemrosesan informasi, serta kapasitas komunikasi. Keberadaan ekonomi digital ditandai dengan semakin maraknya perkembangan bisnis atau transaksi perdagangan yang memanfaatkan internet sebagai media komunikasi, kolaborasi, dan kooperasi antar perusahaan ataupun individu. Gelombang ekonomi digital hadir dengan topografi yang landai, inklusif, dan membentangkan ekualitas peluang (BPPSDM, Kominfo, 2020). Ekonomi digital merupakan sharing economy yang mengangkat banyak usaha kecil dan menengah untuk memasuki bisnis dunia dengan konsep kompetisi yang menjadi spirit industri sehingga mudah terangkat oleh para pelaku startup yang mengutamakan kolaborasi dan sinergi.

Big Data adalah istilah umum untuk ledakan kuantitas dan keragaman data dari high frequency digital data dan biasanya tidak berasal dari sumber tradisional (Pramana, et al., 2017). Big Data memberikan varian baru dalam pemrosesan solusi data dengan manfaat nyata bagi perekonomian. Namun pengolahan data dengan ukuran dan kompleksitas besar tetap sekedar solusi teknologi kecuali jika dikaitkan dengan tujuan bisnis (Efendi, 2018). Big Data yang merupakan himpunan data yang sangat besar dan kompleks menjadikannya sulit bahkan telah dideskripsikan sebagai kumpulan data yang tidak mungkin disimpan dan diproses menggunakan alat perangkat lunak umum apalagi pemrosesan data secara tradisional, terlepas dari daya komputasi atau penyimpanan fisik yang ada. Menurut pandangan ahli statistik, Big Data dapat didefinisikan sebagai data non-sampel, yang ditandai dengan pembuatan database dari sumber elektronik yang tujuan utamanya adalah sesuatu selain inferensi statistik.

Pemerintah Indonesia memiliki misi jangka panjang menjadi The Digital Energy of Asia (Wirabrata, 2016). Salah satu potensi ekonomi digital sektor perdagangan digital dapat dilihat dari banyaknya transaksi yang terjadi pada marketplace. Marketplace merupakan model bisnis baru yang berkembang seiring pesatnya perkembangan infrastruktur teknologi informasi sehingga menjadikannya solusi dari pesatnya perkembangan teknologi informasi dan internet yang menggempur sektor perdagangan. Marketplace dirancang untuk meminimalisir proses bisnis yang kompleks sehingga tercipta efisiensi dan efektifitas dengan indikator ringkasnya waktu dan biaya yang diberikan serta kemampuan marketplace dalam menfasilitasi transaksi, mempertemukan penjual dan pembeli serta menyediakan infrastruktur (Yustiani \& Yunanto, 2017). Dalam marketplace tersebut setiap pelaku usaha dapat menampilkan produknya untuk diperjualkan tanpa perlu repot membangun system. Marketplace mempermudah pelaku usaha kecil dan menengah dalam melakukan operasional. Alasan memperhatikan pelaku usaha tersebut karena Usaha Mikro, Kecil dan Menengah memiliki peranan penting dalam perekonomian di Indonesia (Lembaga Pengembangan Perbankan Indonesia, 2015). Dengan pasar virtual maka para pelaku usaha hanya perlu memberikan informasi selengkap - lengkapnya tentang produk yang mereka jual di marketplace seperti informasi produk, harga, pengiriman dan lainnya.

\section{Tujuan}

Dalam mewujudkan pembangunan ekonomi nasional perlu adanya pembangunan ekonomi daerah yang pada akhirnya mampu mengurangi ketimpangan antar daerah dan mampu mewujudkan kemakmuran yang adil dan merata antar daerah. Salah satu dukungan yang dilakukan agar terwujudnya pembangunan tersebut adalah dengan menyediakan profil dari ekonomi digital yang merupakan tujuan dari penelitian ini. Lebih spesifik tujuan dari penelitian ini adalah memberikan insight untuk menjadi bahan dasar edukasi kepada pemerintah daerah, perusahaan ataupun individu agar lebih memahami ekonomi digital secara umum maupun sektoral hingga potensi yang dimiliki dengan memanfaatan Big Data penjualan barang online pada salah 
satu marketplace yang menjadi acuan dalam membentuk profil ekonomi digital daerah khususnya provinsi Kalimantan Barat.

\section{METODE}

Penelitian ini dilakukan dengan pendekatan kualitatif, yaitu pendekatan yang di dalam usulan penelitian, proses, hipotesis, turun ke lapangan, analisis data dan kesimpulan data sampai dengan penulisannya mempergunakan aspek-aspek kecenderungan, non perhitungan numerik, situasional deskriptif, interview mendalam, analisis isi, bola salju dan story (Musianto, 2002). Berdasarkan pendekatan kualitatif, maka penelitian ini menggunakan jenis deskriptif kualitatif yaitu tidak mencari atau menjelaskan hubungan, tidak menguji hipotesis atau membuat prediksi melainkan bertujuan membuat deskripsi yang secara sistematis, faktual dan akurat. Metode analisis menggunakan metodologi visual site of self, dimana peneliti bertindak sendiri untuk melakukan interpretasi, pemaknaan dan pemahaman terhadap obyek penelitian yang diamati. Dengan kemampuan analisis peneliti membaca dan mengurai makna per bagian yang terbentuk dan dilekatkan kepada obyek gambar visual yang ada (Anggraini, Fianto, \& Riqqoh, 2014).

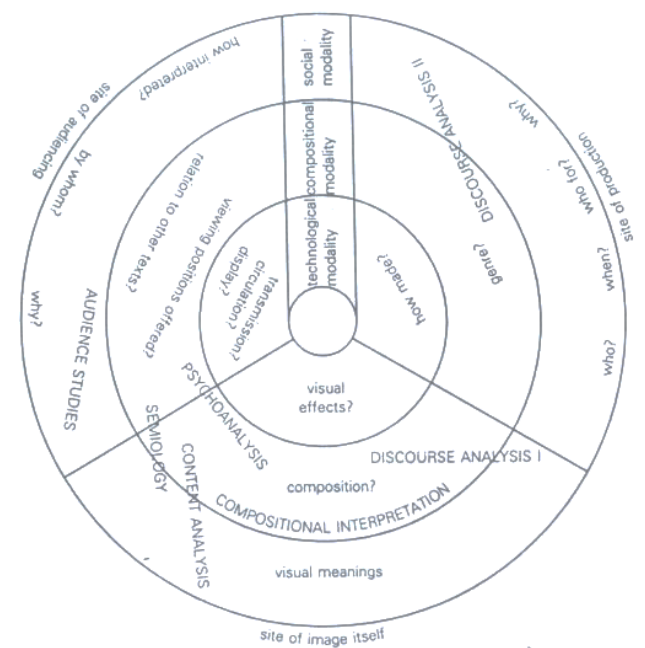

Sumber: Anggraini, Fianto, \& Riqqoh, 2014.

Gambar 42. Site of Image it self, mengarah pada visual meaning.

\section{Teknik Pengumpulan Data}

Teknik pengumpulan data yang dilakukan untuk memperoleh data penjualan pada salah satu marketplace dilakukan dengan cara sumber data diambil secara harian berdasarkan dari informasi yang terdisplay untuk umum dari website marketplace di Indonesia yang dilakukan oleh Subdirektorat Pengembangan Model Statistik, Badan Pusat Statistik Indonesia pada tahun 2020. Penelitian ini menggunakan data periode Januari hingga Maret 2020 dengan cakupan area seKalimantan Barat berdasarakan data yang telah dikumpulkan oleh BPS dan dilakukan data prepocessing menggunakan Data Cleaning dan Effective Files Management dengan cakupan area se-Indonesia. Variabel yang dikumpulkan dan digunakan serta diukur dari data yang diperoleh antara lain jumlah toko online, banyaknya variasi barang, median harga, banyaknya barang terjual, lokasi toko, tanggal pengambilan, dan ketegori barang yang dijual secara online pada marketplace.

Tabel 27. Data Penjualan Pada salah satu marketplace setelah prepocessing.

\begin{tabular}{|c|c|c|c|c|c|c|c|c|}
\hline \multirow[b]{2}{*}{ No } & \multicolumn{3}{|c|}{ Lokasi Toko } & \multicolumn{3}{|c|}{ Kategori Barang } & \multirow[b]{2}{*}{$\ldots$} & \multirow[b]{2}{*}{$\begin{array}{l}\text { Shop } \\
\text { Count }\end{array}$} \\
\hline & Provinsi & Kabupaten & Kecamatan & $\begin{array}{l}\text { Parent } \\
\text { Name }\end{array}$ & Sub Name & $\begin{array}{c}\text { Sub Sub } \\
\text { Name }\end{array}$ & & \\
\hline 1 & $\begin{array}{l}\text { Kalimantan } \\
\text { Barat }\end{array}$ & $\begin{array}{l}\text { Kab. } \\
\text { Ketapang }\end{array}$ & $\begin{array}{l}\text { Delta } \\
\text { Pawan }\end{array}$ & $\begin{array}{l}\text { Aksesoris } \\
\text { Fashion }\end{array}$ & $\begin{array}{l}\text { Aksesoris } \\
\& \text { Set } \\
\text { Perhiasan }\end{array}$ & Bros & $\ldots$ & 2 \\
\hline 2 & Kalimantan & Kab. & Delta & Aksesoris & Aksesoris & Bros & $\ldots$ & 2 \\
\hline
\end{tabular}




\begin{tabular}{|c|l|l|l|l|l|l|c|c|}
\hline & Barat & Ketapang & Pawan & Fashion & $\begin{array}{l}\text { \& Set } \\
\text { Perhiasan }\end{array}$ & & \\
\hline 3 & $\begin{array}{l}\text { Kalimantan } \\
\text { Barat }\end{array}$ & $\begin{array}{l}\text { Kab. } \\
\text { Ketapang }\end{array}$ & $\begin{array}{l}\text { Delta } \\
\text { Pawan }\end{array}$ & $\begin{array}{l}\text { Aksesoris } \\
\text { Fashion }\end{array}$ & $\begin{array}{l}\text { Aksesoris } \\
\text { \& Set } \\
\text { Perhiasan }\end{array}$ & $\begin{array}{l}\text { Set } \\
\text { Perhiasan }\end{array}$ & $\ldots$ & 1 \\
\hline$\ldots$ & $\ldots$ & $\ldots$ & $\ldots$ & $\ldots$ & $\ldots$ & $\ldots$ & $\ldots$ & $\ldots$ \\
\hline 21.240 & $\begin{array}{l}\text { Kalimantan } \\
\text { Barat }\end{array}$ & $\begin{array}{l}\text { Kab. Kubu } \\
\text { Raya }\end{array}$ & $\begin{array}{l}\text { Sei/Sungai } \\
\text { Kakap }\end{array}$ & $\begin{array}{l}\text { Aksesoris } \\
\text { Fashion }\end{array}$ & $\begin{array}{l}\text { Aksesoris } \\
\text { \& Set } \\
\text { Perhiasan }\end{array}$ & $\begin{array}{l}\text { Set } \\
\text { Perhiasan }\end{array}$ & $\ldots$ & 1 \\
\hline
\end{tabular}

Sumber: Subdirektorat Pengembangan Model Statistik, BPS RI.

\section{Teknik Analisis Data}

Data yang berhasil terkumpul dianalisis dengan menggunakan kerangka teoritis metodologi visual aspek visual meanings melalui still image, dengan mengedepankan cara menjabarkan atau menjelaskan visualnya menggunakan site of self. Analisis dilakukan atas dasar visual obyek penelitian berdasarkan fluktuasi atau perubahan yang terjadi, perubahan yang dimaksud adalah pergerakan dari obyek penelitian yang telah dibuat baik itu telah terjadi atau tidaknya perubahan itu sendiri yang dianggap penting sehingga mampu menciptakan serta mempresentasikan suatu profil daerah yang bersangkutan hingga fenomena yang terjadi di sana. Dari sisi lainnya diyakini juga akan menunjukkan potensi pada bagian tersebut atau bagian lainnya yang berkaitan untuk dilakukan analisis lebih lanjut.

Peneliti bertindak sendiri untuk melakukan interpretasi, pemaknaan dan pemahaman terhadap obyek penelitian yang diamati. Dengan kemampuan analisis yang dimiliki peneliti maka peneliti membaca dan mengurai makna per-bagian yang terbentuk dan dilekatkan kepada obyek gambar visual yang ada. Metode analisis deskriptif digunakan untuk menggambarkan perkembangan hasil pemodelan meliputi tabulasi, peringkasan, dan penyajian dalam bentuk grafik atau gambargambar serta perhitungan ukuran deskripsinya. Pertumbuhan (Growth) diukur dengan membandingkan jumlah penjualan pada bulan dasar yang digunakan (Subdirektorat Pengembangan Model Statistik, 2020).

\section{HASIL DAN PEMBAHASAN}

Penelitian ini diharapkan dapat memberikan dampak positif bagi pertumbuhan ekonomi daerah sekitar Kalimantan Barat atau daerah dibelakangnya (hinterland), melalui Big Data berdasarkan data penjualan pada salah satu marketplace. Jumlah data yang berhasil dikumpulkan sebanyak 21.240 dengan rata - rata 7.080 toko selama tiga bulan dan jumlah toko tiap bulannya tidak identik. Merujuk pada pemodelan visual menggunakan data penjualan marketplace BPS secara nasional diketahui bahwa partisipasi provinsi Kalimantan Barat di Indonesia berada pada urutan ke-15 secara kumulatif pada triwulan I tahun 2020 berdasarkan banyaknya toko online dan berdasarkan banyaknya produk terjual berada pada posisi ke-18. Perbandingan partisipasi provinsi Kalimantan Barat dengan provinsi lainnya di Indonesia bisa dilihat pada Gambar $\mathbf{2}$ dan Gambar 3. 


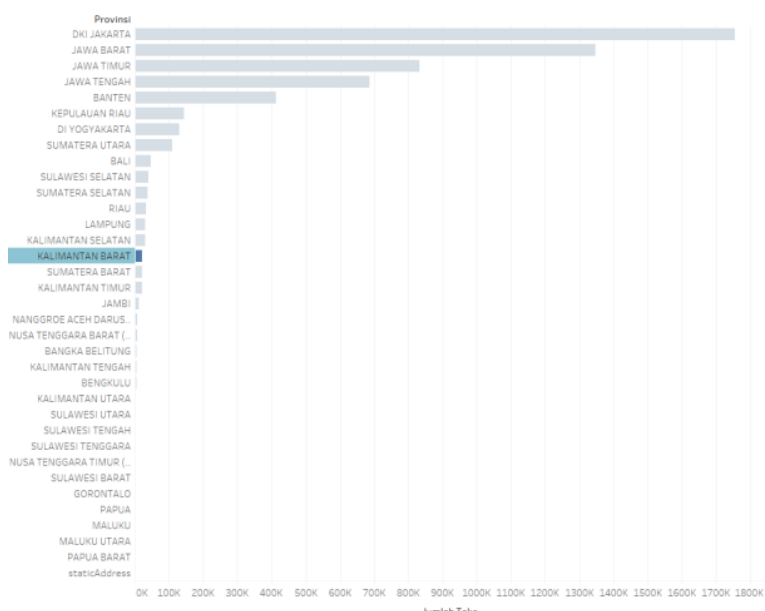

Gambar 43. Partisipasi provinsi Kalimantan Barat berdasarkan banyaknya toko online.

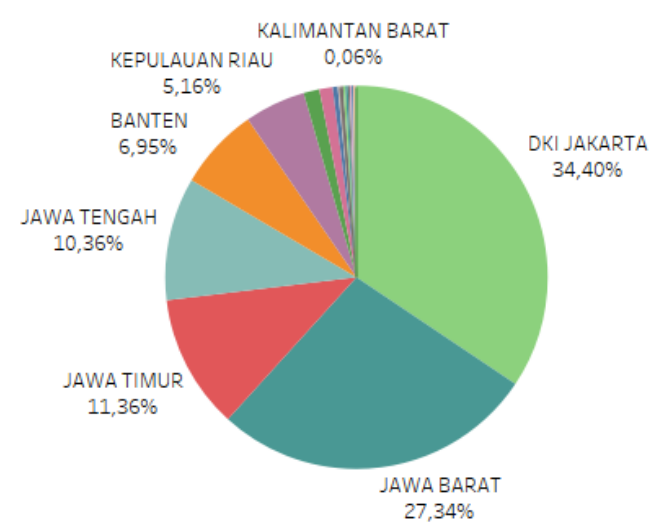

Gambar 3. Persentase partisipasi provinsi Kalimantan Barat berdasarkan banyaknya barang terjual tingkat nasional.

Secara keseluruhan pertumbuhan relatif digital ekonomi di Kalimantan Barat berdasarkan penjualan salah satu marketplace terhadap Januari menunjukkan tren naik. Pergerakan yang terjadi pada Februari mengalami peningkatan yang sangat signifikan yaitu penjualan barang tumbuh hingga tiga kali lipat dari Januari. Dari Gambar 4 terlihat bahwa pergerakan penjualan barang online pada marketplace di triwulan I 2020 mengalami fluktuasi. Walaupun secara keseluruhan pertumbuhan tersebut mengikuti tren naik tapi ada tiga kategori yang mengalami penurunan yaitu aksesoris fashion, perawatan \& kecantikan, dan tas pria. Hal ini menunjukkan bahwa terjadi penurunan minat beli masyarakat pada beberapa kategori yang dijual oleh toko online yang ada di Kalimantan Barat, baik pada bulan Februari mengalami peningkatan kemudian maret mengalami penurunan ataupun yang terus menurun dari Februari hingga Maret 2020.

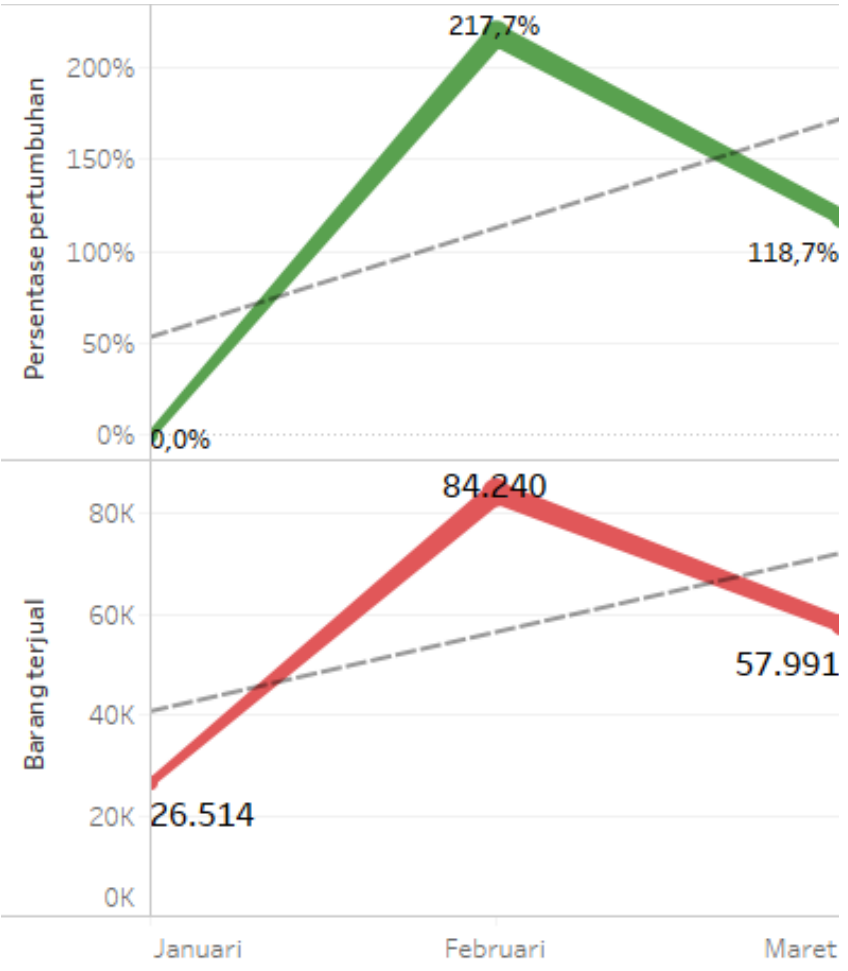

Gambar 4. Penjualan barang online pada marketplace di triwulan I 2020.

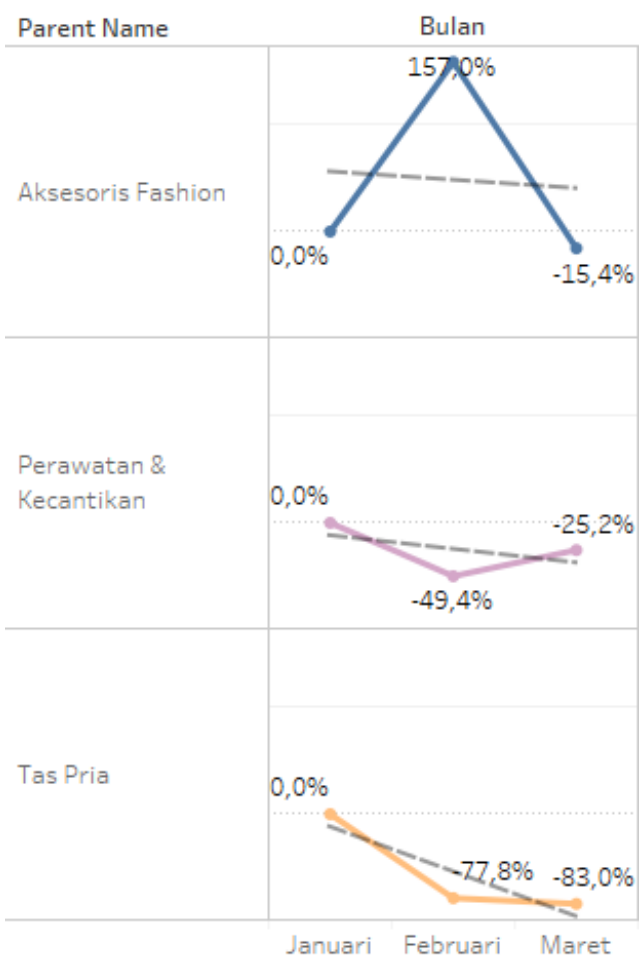

Gambar 5. Kategori yang mengalami penurunan penjualan barang online pada marketplace di triwulan I 2020.

Banyak kategori yang mengalami pelonjakan dalam pertumbuhan penjualannya dengan Januari sebagai bulan dasarnya di Kalimantan Barat. Pertumbuhan untuk setiap kategori yang tertera pada marketplace dengan Januari sebagai bulan dasar menunjukkan bahwa kategori fotografi meningkat pesat pada februari dan maret. Sedangkan kategori Tas Pria terus menurun 
pada februari hingga maret yang mana turun hingga $78 \%$ pada februari dan terus menurun sekitar $5 \%$ sehingga pada maret produk yang terjual di marketplace $-83 \%$ dari produk yang terjual pada Januari. Secara rinci pertumbuhan penjualan berdasarkan kategori parent name yang ada di salah satu marketplace bisa dilihat pada Tabel 2.

Tabel 2. Pertumbuhan berdasarkan kategori pada salah satu marketplace.

\begin{tabular}{lll}
\hline \multicolumn{1}{c}{ Parent Name } & Februari & \multicolumn{1}{c}{ Maret } \\
\hline Aksesoris Fashion & $157 \%$ & $-15 \%$ \\
Buku \& Alat Tulis & $1080 \%$ & $269 \%$ \\
Elektronik & $1229 \%$ & $577 \%$ \\
Fashion Bayi \& Anak & $322 \%$ & $556 \%$ \\
Fashion Muslim & $2252 \%$ & $254 \%$ \\
Fotografi & $22300 \%$ & $14300 \%$
\end{tabular}

$\begin{array}{lll}\text { Hobi \& Koleksi } & 180 \% & 238 \% \\ \text { Ibu \& Bayi } & 414 \% & 605 \% \\ \text { Jam Tangan } & 33 \% & 278 \% \\ \text { Kesehatan } & 598 \% & 346 \% \\ \text { Komputer \& Aksesoris } & 75 \% & 311 \% \\ \text { Perlengkapan Rumah } & 181 \% & 451 \%\end{array}$

Sumber: Hasil olahan peneliti, 2020.

\begin{tabular}{lll}
\hline \multicolumn{1}{c}{ Parent Name } & Februari & \multicolumn{1}{c}{ Maret } \\
\hline Makanan \& Minuman & $2199 \%$ & $467 \%$ \\
Olahraga \& Outdoor & $339 \%$ & $379 \%$ \\
Otomotif & $75 \%$ & $80 \%$ \\
Pakaian Pria & $39 \%$ & $235 \%$ \\
Pakaian Wanita & $23 \%$ & $105 \%$ \\
Perawatan \& & $-49 \%$ & $-25 \%$ \\
Kecantikan & & \\
Handphone \& & $1220 \%$ & $4150 \%$
\end{tabular}

\begin{tabular}{lll} 
Sepatu Pria & $13200 \%$ & $5000 \%$ \\
Sepatu Wanita & $5500 \%$ & $4300 \%$ \\
Serba Serbi & $9400 \%$ & $10800 \%$ \\
Souvenir \& & $1653 \%$ & $453 \%$ \\
Pesta & & \\
Tas Pria & $-78 \%$ & $-83 \%$ \\
Tas Wanita & $1157 \%$ & $1279 \%$ \\
Voucher & $696 \%$ & $272 \%$ \\
\hline
\end{tabular}

Aksesoris

Produk marketplace yang terjual pada triwulan I 2020 di Provinsi Kalimantan Barat didominasi oleh kota pontianak dimana sebaran yang terjadi disana berbeda jauh dengan kabupaten/kota lainnya. Kota pontianak mengambil peran utama dalam pertumbuhan digital ekonomi di Kalimantan Barat, hal ini disebabkan karena Pontianak merupakan ibu kota provinsi sehingga dinilai lebih maju dan mudah dalam proses perpindahan barang serta faktor masyarakat asal Kalimantan Barat yang sudah terbiasa dengan proses perbelanjaan online baik berupa membeli atau menjual produk asal Pontianak sehingga membuat perbedaan yang jelas dengan kabupaten/kota lainnya. Tidak menutup kemungkinan daerah lainnya bisa menyusul pertumbuhan dan perkembangan digital ekonomi marketplace Kota Pontianak di Kalimantan Barat jika dilakukannya pegembangkan dan pemanfaatan infrastruktur yang ada serta pemberdayagunaan SDM(Sumber Daya Manusia) secara maksimal. Peneliti meyakini bahwa setiap daerah memiliki keunggulan masing - masing di dalam sektor perdagangan baik online maupun konvensional sehingga kedepannya bisa ditumbuhkembangkan kedalam digital ekonomi dengan meningkatan wawasan masyarakat dan mengembangan serta meningkatan infastruktur pendukung daerah itu sendiri. 

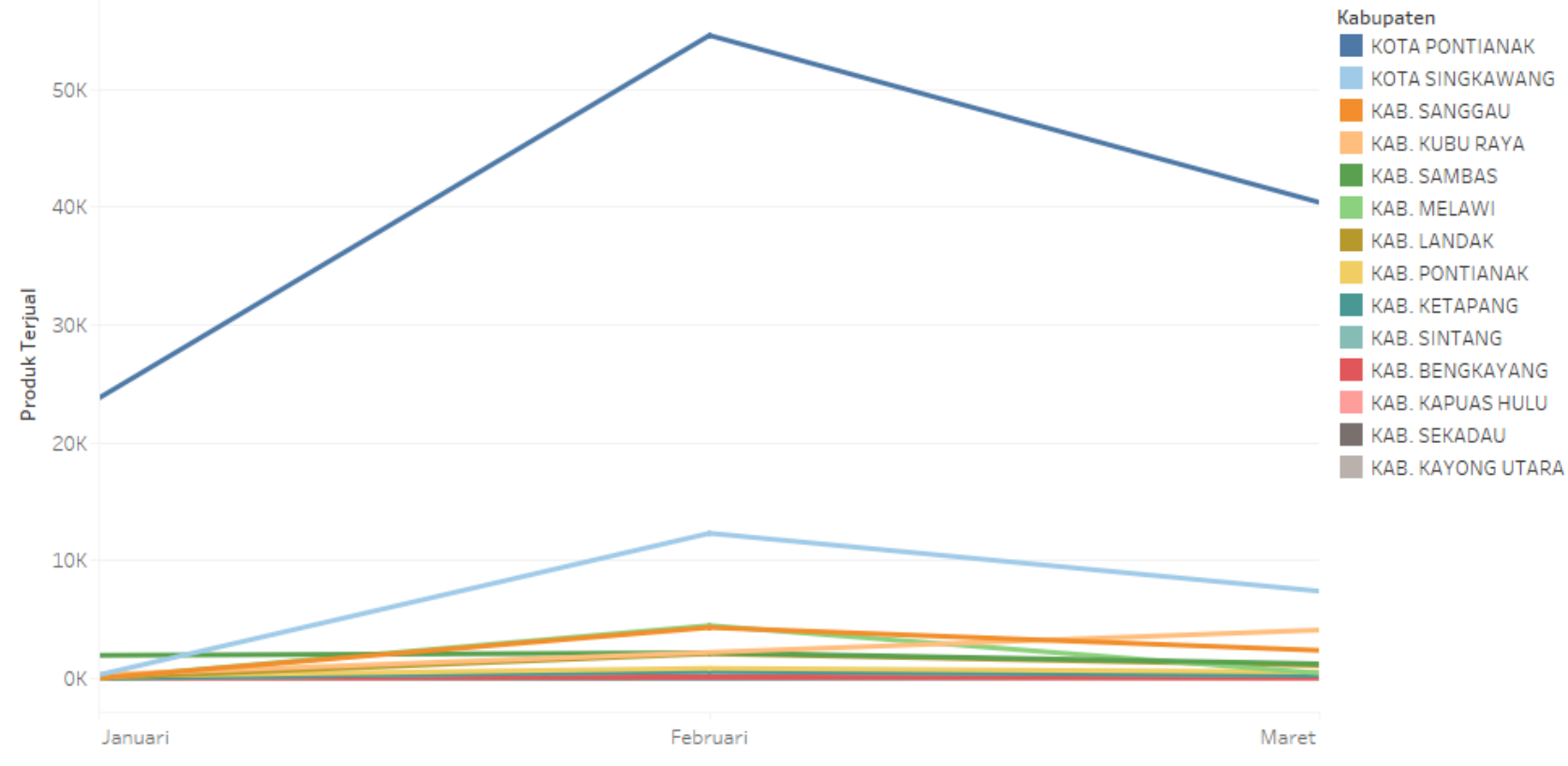

Gambar 6. Penjualan barang online berdasarkan kab/kota di Kalimantan Barat.

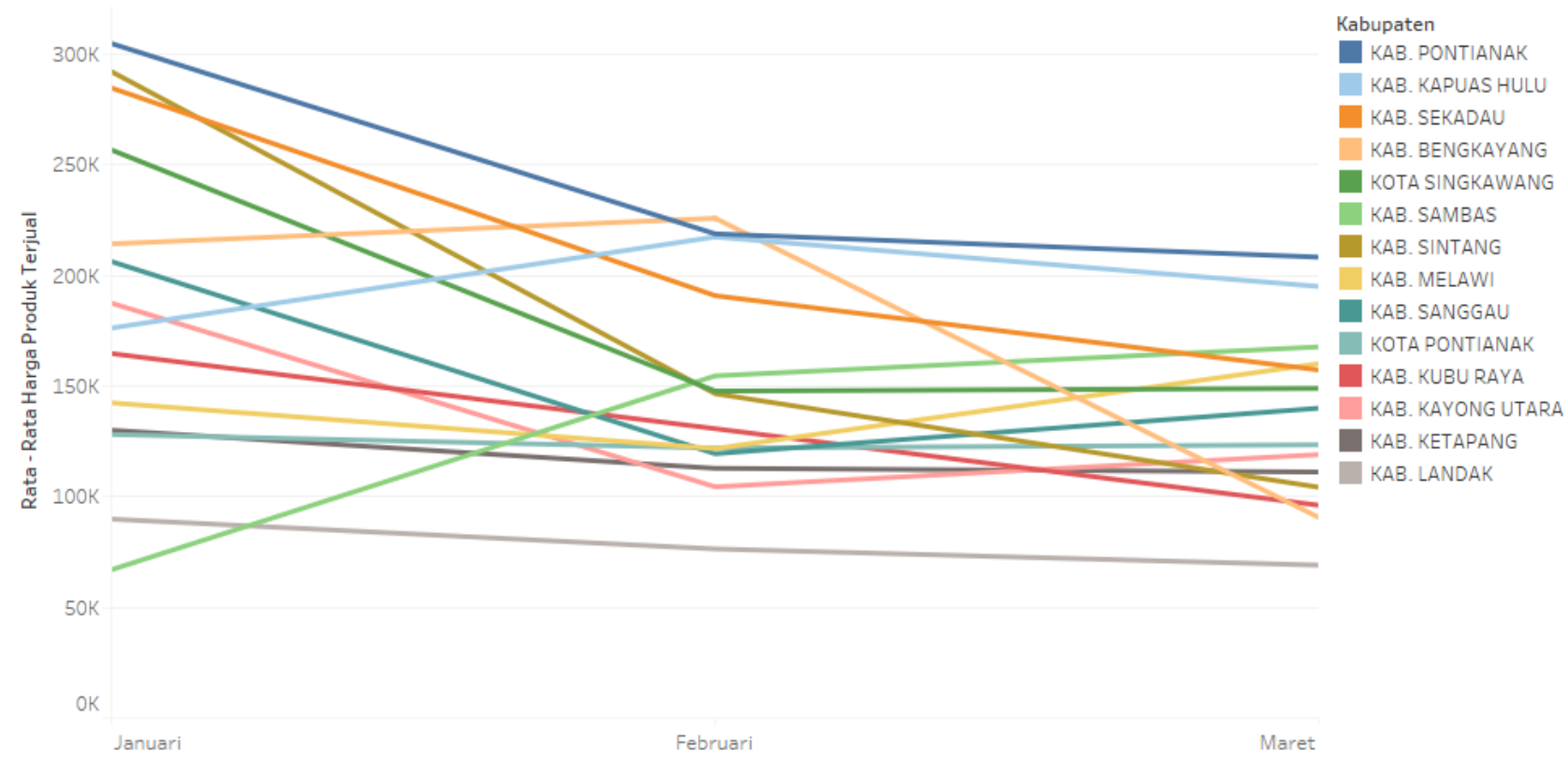

Gambar 7. Pergerakan Harga penjualan barang online berdasarkan kab/kota di Kalimantan Barat.

Produk marketplace yang diperjual-belikan untuk beberapa kabupaten/kota di Kalimantan Barat menurut peneliti memiliki rentang sebaran harga dengan selisih yang tidak terlalu besar sehingga dirasa cukup baik dan stabil. Perubahan harga yang terjadi berkaitan dengan produk yang terjual dinilai cukup wajar sesuai dengan konsep ekonomi yaitu hukum permintaan (law of demand) pada konsep ekonomi mikro. Hukum permintaan menyatakan bahwa asumsi hal lainnya tetap (ceteris paribus), jumlah barang $\left(Q D_{x}\right)$ yang diminta turun manakala harga barang $\left(P_{x}\right)$ tersebut naik, dan sebaliknya. Hukum permintaan yang dijelaskan sebelumnya termasuk dalam ekonomi konfensional yaitu titik beratnya pada harga, jika harga tinggi maka permintaan akan turun, begitu pula sebaliknya (Kasdi, 2016). Setiap kabupaten/kota yang ada di Kalimantan Barat pada maret terlihat bahwa sebaran harga semakin merapat pada akhir triwulan I 2020 sehingga peneliti menduga telah terjadi perubahan harga dibeberapa kategori yang dipengaruhi oleh kondisi kabupaten/kota yang bersangkutan. 


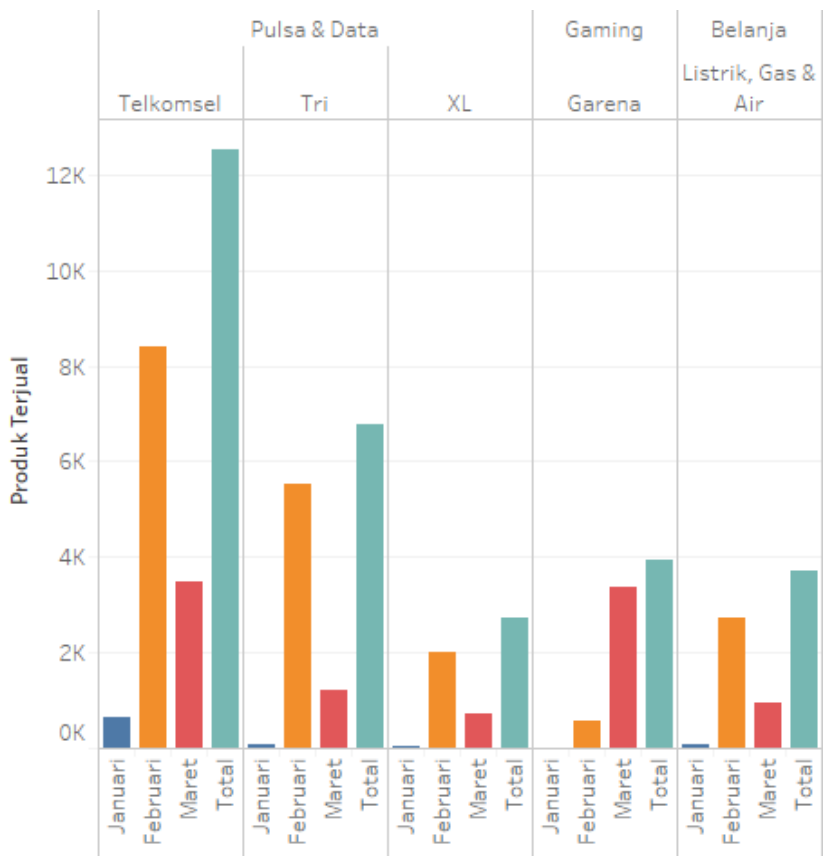

Gambar 8. Tiga jenis barang terbanyak dalam Penjualan barang di triwulan I 2020.

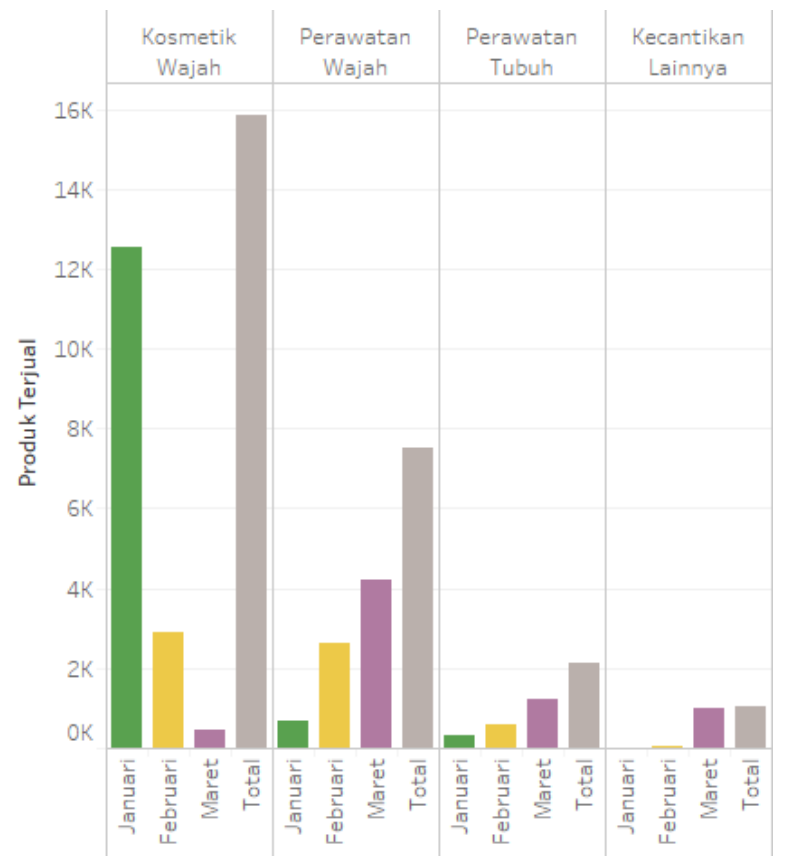

Gambar 9. Komoditas (kategori Perawatan \& Kecantikan) penjualan barang online Kota Pontianak di triwulan I 2020.

Produk terbanyak yang terjual di Kalimantan Barat didominasi oleh kategori Voucher secara berurutan dengan jenis barang Pulsa \& Data, Gaming, dan Belanja berupa produk Telkomsel, Tri, $\mathrm{XL}$, Garena, dan Listrik-Gas-Air. Kota Pontianak dengan penjualan barang terbanyak di Kalimantan Barat menunjukkan kategori Perawatan \& Kecantikan sebagai komoditasnya dengan jenis produk terbanyak berupa Kosmetik Wajah. Jenis produk terbanyak yaitu Kosmetik Wajah di Kota Pontianak dari Januari terus menurun hingga Maret, sedangkan tiga jenis produk dibawahnya terus meningkat pada Triwulan I 2020.

\section{KESIMPULAN}

Pertumbuhan penjualan online relatif terhadap Januari menunjukkan tren naik di Kalimantan Barat hal ini merepresentasikan bahwa ekonomi digital di Kalimantan Barat dapat tumbuh dan berkembang serta mempengaruhi keadaan ekonomi masyarakat secara keseluruhan. Terdapat perbedaan jumlah barang terjual yang terlihat sangat jauh antara Kota Pontianak dengan kab/kota lainnya sehingga mengimplikasikan penetrasi penggunaan marketplace masyarakat Kalimantan Barat tergolong rendah maka diperlukannya peningkatan literasi ke masyarakat baik itu dari segi penjual maupun pembeli. Diperlukannya juga peta jalan membuka akses berbagai macam sektor bisnis untuk masuk, bergabung, mendukung, dan memperkuat bangunan ekosistem ekonomi digital terutama di sektor perdagangan digital di Kalimantan Barat. Ditinjau dari kategori yang telah dikumpulkan banyak kategori yang mengalami pelonjakan dalam pertumbuhan penjualan dengan Januari sebagai bulan dasarnya. Akan tetapi, bukan bearti tidak ada kategori yang mengalami penurunan, hasil olahan peneliti menunjukkan bahwa di Kalimantan Barat pada Triwulan I 2020 terdapat 3 kategori dengan tren menurun.

Saran peneliti kedepannya profil digital ekonomi dapat disajikan dengan dashboard interaktif yang dilengkapi rujukan keseluruh data hasil pengolahan sehingga pengguna dapat lebih mudah memahami dan menggunakan data tersebut. Penelitian lanjutan dengan proses matching data pemerintah mengenai kegiatan ekonomi yang telah dilakukan akan menjadi gambaran arah digital ekonomi terhadap ekonomi masyarakat era modern ini.

\section{DAFTAR PUSTAKA}

Anggraini, R. A., Fianto, A. Y., \& Riqqoh, A. K. (2014). Simbol - Simbol Budaya Dalam Keris Naga Kamardikan Karya Mpu Pathor Rahman. Desain Komunikasi Visual. 
BPPSDM, Kominfo. (2020). Ekonomi Digital Di Indonesia Sebagai Pendorong Utama Pembentukan Industri Digital Masa Depan. Study Ekonomi Digital. Badan Penelitian dan Pengembangan Sumber Daya Manusia, Kementerian Komunikasi dan Informatika RI. Jakarta.

Efendi, I. (2018). Pengertian Big Data. IT-Jurnal.com. Cited in https://www.it-jurnal.com/pengertian-bigdata. [15 September 2020]

Kasdi, A. (2016). Permintaan Dan Penawaran Dalam Mempengaruhi Pasar. Bisnis dan Manajemen Islam, IV(2), 18-34.

Lembaga Pengembangan Perbankan Indonesia. (2015). Profil Bisnis Usaha, Mikro, Kecil dan Menengah (UMKM). Jakarta: LPII dan Bank Indonesia.

Musianto, L. S. (2002). Perbedaan Pendekatan Kuantitatif dengan Pendekatan Kualitatif dalam Metode Penelitian. Jurnal Manajemen \& Kewirausahaan, IV(2), 123 - 136.

Pramana, S., Yuniarto, B., Kurniawan, R., Yordani, R., Lee, J., Amin, I., . . Indriani, R. (2017). Big data for government policy: Potential implementations of bigdata for official statistics in Indonesia. 2017 International Workshop on Big Data and Information Security (IWBIS) (dits. 17-21). Jakarta, Indonesia: IEEE.

Subdirektorat Pengembangan Model Statistik. (2020). Tinjauan Big Data Terhadap Dampak Covid-19. Jakarta: Badan Pusat Statistik.

Wirabrata, A. (2016). Prospek Ekonomi Digital Bagi Peningkatan Pertumbuhan Ekonomi. Info Singkat, $\operatorname{VIII}(17)$.

Yustiani, R., \& Yunanto, R. (2017). Peran Marketplace Sebagai Alternatif Bisnis Di Era Teknologi Informasi. Jurnal IImiah Komputer dan Informasi (KOMPUTA), VI(2), 43-48. 